\title{
EXPERIENTIAL LEARNING VS. SYSTEMATIC PRESCRIPTIONS IN ENGINEERING DESIGN: A CrossroAdS FOR EDUCATION
}

\author{
G. R. Gress \\ University of Calgary \\ grgress@ucalgary.ca
}

\author{
S. $\mathrm{Li}$ \\ University of Calgary \\ simoli@ucalgary.ca
}

\author{
R. W. Brennan \\ University of Calgary \\ rbrennan@ucalgary.ca
}

\begin{abstract}
The systematic, non-experiential prescriptions of classical design methodology continue to have a strong presence in large segments of design research and education while another segment sees domain experience and consequent intuition and creativity as being key to successful design. In this paper the two approaches are outlined and the empirical research literature in human behaviour is employed to discern discrepancies and potential weaknesses. Results show that gaining experience in a domain intrinsically changes how one designs, which the classical methodology does not account for. For example, only designers with tactile and visual domain experience can abstract functions per the dictates of the classical (non-experiential) methodology, which means that they cannot have used the methodology to learn basic design in the first place - or did so only with great difficulty. This and other conflicts pose problems for the education of engineering design students, and to fathom their extent this paper surveys engineering design textbooks offered in Canada and the U. S.; all of the books are found to embrace the classical methodology. If they are to remain involved in preparing students for entry into industry then some aspects of their contained classical methodology must be supplanted by experiential approaches to design education.
\end{abstract}

Keywords: Design education; experiential learning; prescriptive methodology; innate behaviour; engineering pedagogy.

\section{INTRODUCTION}

In 1992, in reaction to the 'scientification' of engineering design as he saw it, Eugene Ferguson maintained that engineering design draws from the experience of patterns initially perceived by our senses, and that "it is only from this sensory experience that the engineer is able to make creative, innovative, yet sound and practical judgments in the process of engineering design" ([43] citing [25]). Epitomizing this so-called scientification was the growth of a systematic and prescriptive design methodology based on Pahl and Beitz's epic book, Engineering Design: A Systematic Approach [56], referred to by many as the 'classical design methodology' [11]:5. Termed the 'cDM' here, its latest incarnations (e.g., [64]) do not require any experience of the designer, nor provide or account for the gaining of experience as one designs [11]:4.

A methodology which in effect does not differentiate experts from novices, however, raises the concern about its appropriateness within an engineering pedagogy, and specifically the question of what might be missing in its use as an educational tool. The cDM may be prescribing activities which students cannot learn from or perform in practice; as such the students would not be adequately prepared for entry into industry.

\subsection{Goals and Methods}

This paper outlines the experiential and systematic approaches to design and uses existing empirical research literature in human behaviour to discern any weaknesses in an approach. It also surveys engineering design textbooks currently available in Canada and the U.S. to fathom the potential extent of corresponding difficulties in design education, and suggests changes based on these findings.

\section{DESIGN AS INTUITIVE PRACTICE}

For one school of thought within design research and education there has been growing evidence to support Ferguson's sentiments, as in Koen's [42]:85 observations that the engineer "recognizes both science and its use as heuristics, albeit very important ones, to be applied only when appropriate." This understanding of engineering design as an intuitive practice represents the current epistemology of design for this school, which is a constructivist reaction against science-inspired methodologies [26]. Typical designing is considered by it to now include compromising, resorting when necessary to non-scientific thinking, and making decisions in the face of incomplete knowledge with the help of intuition and experience [1]. Twenty years ago Lloyd [46] argued that experience is the single most important factor in the solution of design problems. In more general terms, Zuga [66] phrases this as "cognitive processes are useless without content knowledge on which to operate." The school considers this experience to be best gained through 
concrete examples since they are easier to visualize, and provide the learner with a guide to understanding new, abstract representations in the world. Learners can test that understanding by visualizing what would happen if it were true and decide that it is consistent with their experience. Design learning and experience require feedback, and interaction with the environment provides the best and most generalizable feedback [1]. Accordingly, educators within this school would look for examples in the students' experiences to illustrate theories and principles. Otherwise, the students will revert to memorizing the principle without connecting it to the world [1]. Similarly, working within experiential environments would be conducive to learning both design and the connections to underlying principles.

\section{DESIGN AS SYSTEMATIC PRESCRIPTION}

A second school of thought within design research and education remains committed to science-inspired methodologies, especially the cDM, believing that engineering design itself is or should be a scientific process [16], dictated by rules external to and independent of the designer. It is a mantra perhaps still well epitomized by the proclamations made thirty years ago by Hubka and Eder [34], [33]:

\footnotetext{
"The most strongly established discipline in engineering design is that of design methodology. It has appeared in various countries in response to a worldwide dissatisfaction with traditional procedures of designing, which are considered as results of creativity and intuition."
}

The methodology's approach has been to embrace systematic, non-visual and non-tactile design methods such as abstract functional analysis (e.g., [56], [65]) to: rationalize the design process [9], [11]:5; make it universal and independent of the artifact ([54] citing [5]) and; eliminate the highly variable human parameters of experience and creativity for the purposes of increasing efficiency, effectiveness and design-outcome certainty ([11]:4, citing [56]).

\subsection{Origins of Classical Design Methodology}

The development of formal design methods began in the 1940s and 1950s with the recording of experiences and individual findings by several engineering designers such as Wögerbauer, Kesselring, and Pahl [36]. One of their aims was to impart their experience and findings onto beginners to ease and shorten the time necessary to become a fully-fledged designer.

In their further development, design methods became more comprehensive and abstract in order to gain scientific recognition and be suitable for a broad application in different design domains [36]. A distinguishing feature of their development was the belief that logic and rational procedure are themselves the foundations of design [54].

In Germany, the design methods converged to the formal design guideline VDI 2222 [36]. It was comprised of four main design phases: clarification of task (or problem definition); concept generation; embodiment design, and; detail design, which essentially reduce to analysis-synthesis. Included in the guideline were pieces of advice, such as "To free oneself of fixation on solutions, it is advisable to start with the abstraction of the task" and action-oriented instructions like "[set] up a function structure." In 1993 the guideline was replaced by an even more abstract one, VDI 2221, in whose development Pahl and Beitz were heavily involved, and whose design process flow chart is still representative of today's widely-used cDM [36].

\subsection{Concept Generation Phase}

If any of the four systematic design phases listed above were to conflict with human tendencies, concept generation would be likely be the candidate, linked as it is to creativity. It is likely too then that any discrepancies between the experiential and systematic design approaches will be found here. Per the example of its originators (Pahl and Beitz [56]), the cDM's concept generation phase is usually comprised of the following four steps: functional analysis and decomposition; systematic solution search (or non-experiential creation); systematic and morphological combination; systematic concept selection (which, for simplicity, we have taken the liberty to include, though it will sometimes comprise its own chapter in a design textbook, eg., [65]). Of these, functional analysis and decomposition is considered here first, because it most fully and explicitly epitomizes the systematic, non-visual and non-tactile mandate of the cDM.

\subsection{Functional Analysis and Decomposition.}

The cDM's functional analysis and decomposition step initially comprises the use of a 'black box' to represent the product function, as shown in the top image of Fig. 1 (adapted from [65]:122, and [53]:152, 574). Subsequently, the single black box is divided "into subfunctions to create a more specific description of what the elements might do" [65]:122. As many black boxes as needed are combined hierarchically in flowchart form to represent the complete product function. The goal of this representation is to describe the functional elements of the product without implying a specific physical solution concept [65]:123, hence the 'abstract' designation sometimes given functional analysis. By defining the interactions of functions in terms of transformations of energy, material, and signal flows instead, the intent is to provide an intermediate step between problem and concept solution. The goal of decomposition, in turn, is to separate complex problems into simpler ones, for which solutions are to be found using the subsequent step of systematic solution 
search. As in functional analysis, this subsequent step is prescribed without reference to prior experience or to a proficiency level of the designer. Systematic solution search and the other remaining steps within the concept generation phase are further discussed in Sect. 3.2.
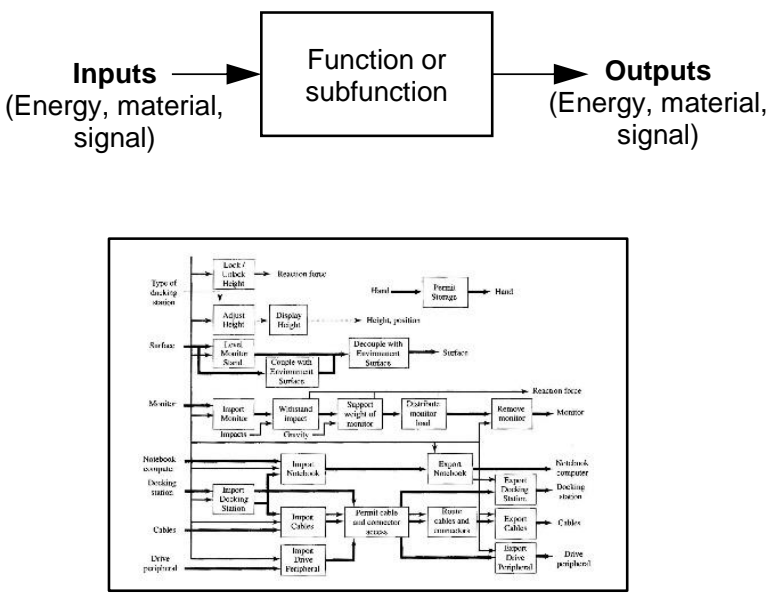

Fig. 1. Top: Black box function representation. Bottom: Typical product-function structure using black boxes.

\section{HUMAN BEHAVIOUR IN DESIGN}

The following subsections utilize the empirical research literature in psychology, education and design to elucidate the human traits considered here to be possibly relevant to designing, some of which are: learning; abstraction, and; visualization. Not all references will be direct empirical research, but may instead cite them.

\subsection{Abstraction Requires Experience in Domain}

For many engineering designers, functions are hard to imagine except as the actions of concrete spatial things that they obtain through, for example, memories of machines that embody those functions [62], [37]. Empirical research has shown that conceptual knowledge is always linked first to devices rather than abstractions - as is the case in science [48]; a concept in design derives from multiple exposures to the artifacts which embody it [62], [45]. Similarly, function is abstracted from form after witnessing many examples, and the resulting generalized knowledge's hierarchical structure [12], [54] allows the designer to readily recognize underlying meaning in similar design situations [54], [30].

It is deducible, then, that students without domain experience will have nothing to abstract, and that they will have difficulty thinking in terms of functions because none have been formed in their minds. With no visual or tactile experience to draw upon, they will necessarily try to use deductive reasoning to solve design problems [28], with little chance of progressing past the problem scoping stage [7].

\subsection{Coexistence of Visualization and Experience}

But even design engineers who manage to be trained analytically only remain so until they acquire experience with the specific problem type; after that they will automatically visualize solutions [47]. Recognition and interpretation of design problems already begins in the human visual system, and good spatial ability significantly promotes design success [2], [27], but only once the designer has gained tactile experience from which to draw upon [27]. This change which occurs as experience in the domain is gained cannot be avoided, for electroencephalography (EEG) experiments performed during conceptual design have shown that experts use more of the visual-spatial regions of their brains than novices do [28]. The ability is comprised of making meaningful interpretations of visual stimuli and of the relations between stimulus elements [29]. The human visual system is a network of many subsystems that interact to give meaning and find the essence of things, thereby making new connections and leading to transformations in memory [10]. This is the mechanism by which one then visualizes and recognizes solutions in terms of one's own experiences [39], [54], [38]. It is also the mechanism - or is similar to the mechanism - by which one learns, as will be seen in the following subsection.

With this acquired visualization ability, ideas will still need to be expressed in concrete form to see how useful they are. It is through externalized modelling techniques that such complex ideas can be expressed and clarified, thus supporting the next stage of cognitive modelling [41], and which implies an iterative-making aspect to design.

\subsection{Gaining Experience Gradually - by Necessity}

The information stored in a person's long term memory is continually being rewritten or transformed with new experiences and reflections [61] according to a structure which supports exploration and creativity [54]. Efficient retrieval requires that the presentation of stimuli be greatly slowed down, accomplished through protracted learning and the accumulation of experience, and the use of external memory aids [19]. The time required to learn is exacerbated by the need to present the stimuli more than once, with distinct pauses in between [4], [52]:116.

Brereton [14] found that physical components or artifacts are integral to learning in the field of design, and positively affect the course of inquiry, idea generation and discovery. Engineering students learn engineering fundamentals and develop engineering intuition by relating abstract engineering theory to their interactions with hardware - or 'doing' [59]. Building a foundation of physical activities and sensing, with materials and devices, is seen as critical preparation for performing engineeringoriented visualization [60] and sketching [15]. Various recent studies have shown significant improvements in engineering students' understanding of system 
interconnectivity, and increased abilities to describe reasonable redesign solutions after performing scaffolded design dissection - or reverse engineering - activities [15].

\subsubsection{Foundations: Learn in Terms of What You Know}

Any such learning, however, must be built up, starting with very simple experiences and problems which are limited by the size of short term memory [52]:118, [55]. Subsequent increases in difficulty must lie within these limitations as well, so that they can be incorporated into memory schemas or chunks (c.f. [49]). Indeed, Ericsson [23] observed that students and advanced performers should be presented with cases just above their current level of ability. People only learn by connecting what they are learning to what they already know, and therefore instruction should build on the learners' prior knowledge and understanding [1], their foundation at any given time.

Eysenck [24] showed how such memory indexing leads to favorable design outcomes, whereby the success of problem-solvers rests primarily on their ability to correctly select a very small part of the total problem-solving maze for exploration. People learn through experience which elements of the situation are important and which can be ignored [20]. This makes for easier understanding and expedient selection from an otherwise infinite array of solutions for the competent designer. As Bagiati and Evangelou [8] noted, engineering would be difficult to practice if engineers had to reinvent the wheel every time they tried to address a need; they must have the ability to recall previous solutions. It is also the only way designers will see a problem once they have some experience in the domain [47]. These abilities manifest themselves as emotions, for it has been found that experience at or above the level of competency reveals itself as developing a 'feel' or having intuition for choosing what to do [20], [22].

Therefore, investing in the lengthy practices of learning and gaining experience allows one to reap the reward of being able to design with relatively low cognitive expenditure; i.e., using the very limited real-time resources available to humans.

\subsection{Creativity Accompanies Experience}

As was discussed in Sect. 4.3, knowledge structures in the human brain are organized to support the process of exploratory thinking which is characteristic of design. Performing this exploration and being able to search through memory structures to select relevant knowledge can be regarded a part of the creative process [54]. But these structures not only create a space for existing learning, they allow learners to anticipate where not-yetdiscovered ideas should fit; our brains are hardwired to look for patterns in what we experience, and those patterns become the basis for future action and learning, allowing the learner to adapt to new situations and come up with new ideas [1]. Once people acquire some experience in a domain they will inherently be creative in it, and are bound to apply that creativity to new design problems [44].

\section{DIFFICULTIES WITH PRESCRIPTIONS}

It is readily seen that the greatest misalignment with the foregoing human behaviour descriptions comes from systematic-prescription school, or that portion of the cDM which has been discussed so far. Abstraction, prescribed by the functional analysis step, cannot be performed without first having tactile and visual experience in the domain - which is a contradiction of the cDM mandate. Experience with physical artifacts is integral to continued learning and to improved product outcomes, but the cDM neither prescribes nor advocates the gaining of any such experience.

It is also found that acquiring domain experience which ultimately is unavoidable - automatically causes the designer to creatively visualize solutions when faced with design problems. This will likely circumvent all of the steps in the cDM's concept generation phase (Sect. 6), not just functional analysis.

\subsubsection{Mistaken Directive(s) from the Beginning?}

From this result a question then arises: why did the fathers of the cDM, very experienced designers themselves, advocate abstraction to beginners (Sect. 3.1)? We know that one of their purposes was to impart their methods onto beginners to reduce the time necessary to become full-fledged designers. Perhaps they did not realize that abstraction only comes from experience itself, and that one cannot simply instruct beginners to behave like experienced designers and expect better results. As was discussed in Sect. 4.3, one learns only gradually, and only in terms of what one already knows.

\section{ENGINEERING DESIGN TEXTBOOKS}

It appears that there is no unified engineering pedagogy which acknowledges and works with this need to gain experience in design. Crismond and Adams [15] describe engineering design textbooks as often espousing design techniques and steps over how people actually learn design. And, as Van Dooren et al [19] note, for experienced designers the design process is not split up into separate steps but is an undivided whole, with automatic actions based on routine and with moments of reflection and exploration. To determine whether common engineering design textbooks allow for and provide guidelines for gaining design experience, or advocate following the cDM's systemized and universal steps, several were surveyed for this research.

\subsection{Textbook Research Methodology}

6.1.1. Material Collection. The University of Toronto and University of Calgary online libraries were searched for book titles using the word "design" along with one or 
more of the words "engineering", "product" and "mechanical." The first criteria for selection from the results were that the book cannot be specific to a discipline, as in "engineering design of concrete structures," and that it must involve a design process, i.e., activities leading to the production of a product. This precluded books focused on the selection and application of components, such as Shigley's Mechanical Engineering Design [51]. The final criterion of a book's publication date in the library listings being later than 1999 resulted in 12 textbooks remaining, and these are listed in Table1. Publisher websites were subsequently checked for book availability, with two books no longer being offered (indicated by shading in their respective rows on the left half of Table 1) and two having newer editions than those in the library listings (titles shown in bold in Table 1). Rather than acquiring these new editions, their online table-of-contents postings were crosschecked with the library editions to confirm that there were no substantial differences. The publishing date and page numbers therefore correspond to the older editions in these two cases.
6.1.2. Material Evaluation. Each of the books' content was examined for the presence of any abstract, nonexperiential aspects of design, and for aspects involving physical interactions and experience with the environment. The detailed categories in Table 1 manifesting these aspects are described below, and their relative strengths are represented by the degree of shading in the table. Darkshaded blocks designate a strong and explicit presence of the item in a textbook, whereas light-shaded ones indicate weak or casual usage. Unshaded blocks with page numbers represent an indirect or implicit reference to the item, or an item which has no link to or causative effect on the contained design process.

From our experience, a concept generation phase whose steps are listed in Sect. 3.2 - is indicative of the $\mathrm{cDM}$ being prescribed by the textbook. As can be seen from Table 1, the twelve textbooks contain all or most of the cDM concept generation steps - and most strongly so. The subsections to follow will look at some of these steps in more detail, and how they relate to the learning and practice of design engineers.

Table 1: Engineering design textbooks: Prevalence of experiential and non-experiential sections.

\begin{tabular}{|c|c|c|c|c|c|c|c|c|c|c|c|}
\hline \multirow[b]{2}{*}{ Title } & \multirow[b]{2}{*}{ Author(s) } & \multirow[b]{2}{*}{ Major sources or citations } & \multicolumn{3}{|c|}{$\begin{array}{c}\text { Abstract, non- } \\
\text { experiential sections }\end{array}$} & \multicolumn{6}{|c|}{ Physical, experiential sections } \\
\hline & & & 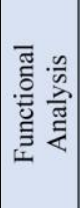 & 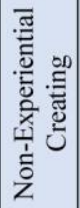 & 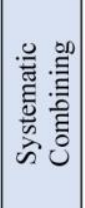 & 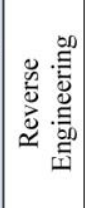 & 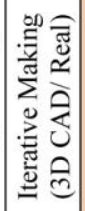 & 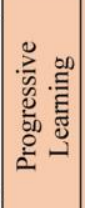 & 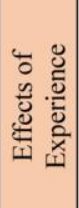 & 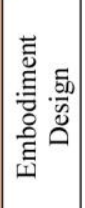 & 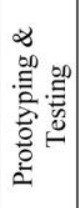 \\
\hline Engineering Design & $\begin{array}{c}\text { Dieter \& } \\
\text { Schmidt, } 2013 \\
\end{array}$ & $\begin{array}{c}\text { (Ulrich \& Eppinger, 2012), } \\
\text { (Ullman, 2010), }\end{array}$ & $216-226$ & $192-216$ & $226-241$ & $86-87$ & & 196,201 & 196,201 & $299-385$ & $372-378$ \\
\hline \begin{tabular}{|c|} 
Engineering Design: \\
A Project-Based Intro
\end{tabular} & $\begin{array}{c}\text { Dym \& Little, } \\
2009\end{array}$ & $\begin{array}{l}\text { (Ulrich \& Eppinger, 1995) } \\
\text { (Ullman, 1997, 1992) }\end{array}$ & 79-101 & & $102-126$ & \begin{tabular}{|l|}
$85-87$ \\
\end{tabular} & & & & & $164-188$ \\
\hline Engineering Design & Eggert, 2005 & $\begin{array}{c}\text { (Pahl \& Beitz, 1996) } \\
\text { (Ullman, 1997) }\end{array}$ & $76-81$ & 81 & $82-84$ & 30 & 172 & & & $145-172$ & $207-223$ \\
\hline $\begin{array}{c}\text { Engineering Design } \\
\text { Process }\end{array}$ & $\begin{array}{l}\text { Haik \& Shahin, } \\
2011\end{array}$ & $\begin{array}{c}\text { (Pahl \& Beitz, 1996), } \\
\text { (Ulrich \& Eppinger, 1995) }\end{array}$ & $\mid 133-151$ & |179-182 & 174 & $144-150$ & 216 & & & 213 & 216 \\
\hline $\begin{array}{c}\text { Fundamentals } \\
\text { of Design Engineering }\end{array}$ & Hyman, 2003 & $\begin{array}{c}\text { (Dieter, 1991), } \\
\text { (Otto \& Wood, 2001), }\end{array}$ & $57-62$ & $248-271$ & $272-280$ & & 27 & & 261 & & $27-28$ \\
\hline Product Design & $\begin{array}{l}\text { Otto \& Wood, } \\
2001\end{array}$ & $\begin{array}{l}\text { (Ulrich \& Eppinger, 1995), } \\
\text { (Pahl \& Beitz, 1996) }\end{array}$ & $|147-195|$ & 418-433 & $421-476$ & $197-257$ & $838-889$ & $197-257$ & 150 & $535-600$ & 838-977 \\
\hline $\begin{array}{l}\text { Engineering Design: A } \\
\text { Systematic Approach }\end{array}$ & $\begin{array}{c}\text { Pahl \& Beitz, } \\
2007\end{array}$ & $\begin{array}{c}\text { (Pahl \& Beitz, 1996) } \\
\text { VDI } 2222 \text { (see Cross, 1993) }\end{array}$ & $\mid 161-178$ & 181-183 & $\mid 184-225$ & & & & 182 & $227-438$ & 133 \\
\hline $\begin{array}{l}\text { Product Design for } \\
\text { Engineers }\end{array}$ & Shetty, 2016 & $\begin{array}{l}\text { (Ulrich \& Eppinger, 2012), } \\
\text { (Cross, 2008) }\end{array}$ & 75-134 & $55-56$ & $57-129$ & & $\mid 386-398$ & & & $|159-227|$ & $389-392$ \\
\hline $\begin{array}{l}\text { The Mechanical } \\
\text { Design Process }\end{array}$ & Ullman, 2010 & $\begin{array}{c}\text { (Ullman, 1997, 1992) } \\
\text { (Pahl \& Beitz, 1996) }\end{array}$ & 181-189 & $\begin{array}{c}64-66 \\
189-204\end{array}$ & 204-208 & $176-181$ & & & xi,65-66 & $241-276$ & 308-313 \\
\hline $\begin{array}{l}\text { Product Design and } \\
\text { Development }\end{array}$ & $\begin{array}{c}\text { Ulrich \& } \\
\text { Eppinger, 2012 }\end{array}$ & $\begin{array}{l}\text { (Pahl \& Beitz, 2007), } \\
\text { (Hubka \& Eder, 1988) }\end{array}$ & $\mid 120-123$ & $124-134$ & $130-140$ & & 301 & & & & $289-309$ \\
\hline $\begin{array}{l}\text { Designing Engineers: } \\
\text { An Introductory Text }\end{array}$ & $\begin{array}{c}\text { (McCahan et al, } \\
\text { 2015) }\end{array}$ & $\begin{array}{l}\text { (Hirtz, et al, 2002), } \\
\text { (Dieter, 2000) }\end{array}$ & 96-107 & $134-139$ & $141-143$ & $115-121$ & $|167-184|$ & & & $\mid 194-201$ & $\begin{array}{c}53-54, \\
178\end{array}$ \\
\hline $\begin{array}{c}\text { Engineering Design } \\
\text { Methods }\end{array}$ & (Cross, 2008) & $\begin{array}{c}\text { (Pahl \& Beitz, 1996), } \\
\text { (Ulrich \& Eppinger, 1995) }\end{array}$ & 93-104 & $48-58$ & $138-149$ & & 22 & & $\begin{array}{c}25-27 \\
54\end{array}$ & & \\
\hline
\end{tabular}


Also heading Table 1 are categories indicative of a physical, experiential approach: reverse engineering; early iterative making (3D CAD or real); embodiment design; and formal prototyping and testing. Two others which we consider important to the experiential approach, Progressive Learning (layered foundations) and Effects of Experience, are included in Table 1; it shows the texts to contain very little material related to either. As well, it was found that if a text contains a Reverse Engineering section, it is usually in support of functional analysis or to aid the understanding of functional structure (e.g., [32]) rather than for the accumulation and structuring of experiential knowledge. Prototyping \& Testing, of course, is mandatory for successfully introducing physical products into the world, and so its reasonably strong presence in Table 1 is not considered indicative of an experiential mandate like Iterative Making would be.

\subsection{Remaining Steps of cDM Concept Generation}

Functional analysis and its relation to human behavior have already been discussed in Sects. 3.3 and 5. The following subsections briefly address the remaining steps of the cDM's concept generation phase similarly, with reference to the textbooks listed in Table 1.

6.2.1. Problem Definition. The cDM's functional analysis step will usually include or be preceded by an extensive problem analysis or definition phase, thought by some to be too extensive [13], [31], and so is included here. Based on the human behaviours described in Sect. 4, there can be no inherent structure in a situation since one learns the problem in terms of one's own experiences. As Figueiredo [26] observes, "the process of solving a problem becomes identical with the process of understanding its nature, $[\ldots]$ with the information needed to understand the problem depending on the designer's ideas for solving it." Atman et al [6] found that novices having no experience and therefore no ideas - could not produce quality designs in spite of spending a large portion of their time defining the problem.

\subsubsection{Systematic Solution Search (or Non-Experiential} Creation). Eleven of the design textbooks listed in Table 1 prescribe various systematic search techniques for embodying the abstract subfunctions derived from the functional analysis step and turning them into artifacts. But merely browsing through images or trying to consult specialists as advocated by the cDM design-text authors (e.g., [65]:125-126) - in lieu of gaining actual, hands-on experience - neither helps design students learn nor helps them solve design problems. In empirical studies of design students, Radcliffe \& Lee [57] found that the subjects turned the pages of design magazines in an apparently aimless fashion, and that their search for solution ideas was constrained by their knowledge and experience. This finding is very similar to that of Samuel [58], wherein students were unable to interact with specialists ([57] citing [58]).

Some of the design textbooks advocate general creativity exercises (e.g., [35] pp. 269-271), that is, the teaching and learning of creativity on its own or as its own domain. There are some researchers and educators who advocate doing so as well (e.g., [18]). However, as discussed in Sect. 4.4, once people acquire experience in a domain they will be creative in it anyway.

\subsubsection{Systematic and Morphological Combination} Some examples of systematic combinatorial methods are the concept classification tree and the concept combination table (e.g., [65] pp. 131-138), intended to bring the large number of random, systematically-generated sub-solution combinations down to a manageable level. The arguments against these activities are the same as those against functional analysis and systematic solution search, that one visualizes and recognizes solutions based on one's experiences, and makes creative transformations of those experiences [39], [54]. The testing of and reflection upon those solutions form the basis of learning and design, and become new experiences themselves.

6.2.4. Systematic Concept Selection Methods. Alves et al [3] found that, in practice, designers shunned rational convergence techniques for being too systematic, and adopted instead intuitive decision processes, making spontaneous choices based on their own strategic perspectives. Kihlander [40] observed that formalized selection methods such as concept scoring and weighed objectives method often have little significance in design practice, and that formal decision making plays a minor role.

\subsection{Is the cDM a Model of Expert Designers?}

From the foregoing analyses and discussions, the cDM's concept generation phase may be thought of as a model of expert designers, albeit a very crude one, which attempts to emulate their design outcomes but without an understanding of the human processes involved.

\subsubsection{Lack of cDM Use in Industry: An Explanation}

It is possibly for these reasons that the cDM is rarely used in industry by practicing designers, regardless of their educational backgrounds [17]:5, [11]:1, [21], [44], [50], [63]. Experienced designers likely do not need a device which attempts to emulate or replace themselves, especially via artificial and systematic directives. What they may want, instead, is one that works with and extends their abilities.

\section{CONCLUSIONS}

Based on human behaviours described in the empirical research literature, the classical design methodology is found to prescribe activities which beginning designers 
have difficulty performing (e.g., functional abstraction), It also does not allow for activities that experienced designers are automatically and naturally inclined to do (such as visualize solutions). The cDM will need to incorporate and allow for physical experience in its mandate if it is to be usable and workable for designers across the proficiency spectrum.

The systematic concept generation phase of the cDM may, in effect, be an attempt at emulating expert designers and their processes, without understanding either. This may be the reason the $\mathrm{cDM}$ is rarely used by practitioners in industry: there is no need to emulate what you are already inclined to do. A better DM would be one that extended a designer's abilities.

All design methodologies, if they are to be successful at all - within education or outside it - must be written with an understanding of human behaviour, of the importance of human designers gaining tactile and visual experience with artifacts in the domain, and of the profound and unavoidable changes which occur as one gains that experience.

It is also found that the cDM pervades all or most of the engineering design textbooks available in North America, which possibly implies that it is a dominant factor in design education there. To better prepare engineering design students for industry, it may be advisable that educators circumvent the systematic concept generation phase of the cDM, and supplant it with a pedagogy which understands, works with, and builds upon the behavioural tendencies of human designers.

\section{References}

[1] R. Adams et al., "Multiple Perspectives on Engaging Future Engineers," J. Eng. Educ., vol. 100, no. 1, pp. 4888,2011

[2] O. Akin, "Necessary conditions for design expertise and creativity," Des. Stud., vol. 11, no. 2, pp. 107-113, 1990.

[3] J. Alves, M. J. Marques, I. Saur, and P. Marques, "Creativity and Innovation through Multidisciplinary and Multisectoral Cooperation," Creat. Innov. Manag., vol. 16, no. 1, pp. 27-34, 2007.

[4] J. R. Anderson, The architecture of cognition. New York: Psychology Press, 1983.

[5] L. B. Archer, "The structure of design process," in Design Methods in Architecture, G. Broadbent and A. Ward, Eds. New York: George Wittenborn, 1969.

[6] C. J. Atman and K. M. Bursic, "Teaching Engineering Design: Can Reading a Textbook Make a Difference?," Res. Eng. Des., vol. 8, pp. 240-250, 1996.

[7] C. J. Atman, R. S. Adams, M. E. Cardellla, J. Turns, S. Mosborg, and J. Saleem, "Engineering Design Processes: A Comparison of Students and Expert Practitioners," J. Eng. Educ., no. October, pp. 359-379, 2007.

[8] A. Bagiati and D. Evangelou, "Practicing engineering while building with blocks: identifying engineering thinking," Eur. Early Child. Educ. Res. J., vol. 24, no. 1, pp. 67-85, 2016.
[9] L. Ball, N. J. Lambell, S. E. Reed, and F. J. M. Reid, "The Exploration of Solution Options in Design: A 'Naturalistic Decision Making' Perspective," 2001.

[10] A. M. Barry, "Perceptual aesthetics: Transcendent emotion, neurological image," Vis. Commun. $Q$., vol. 13, no. 3, pp. 134-151, 2006.

[11] H. Birkhofer, The Future of Design Methodology, no. 1. Springer, 2011.

[12] T. A. Björklund, "Initial mental representations of design problems: Differences between experts and novices," Des. Stud., vol. 34, no. 2, pp. 135-160, Mar. 2013.

[13] D. Braha and O. Maimon, "The Design Process: Properties , Paradigms , and Structure," Syst. Humans, vol. 27, no. 2, pp. 146-166, 1997.

[14] M. F. Brereton, "The role of hardware in learning engineering fundamentals: An empirical study of engineering design and disection activity," Stanford University, 1999.

[15] D. P. Crismond and R. S. Adams, "The informed design teaching and learning matrix," J. Eng. Educ., vol. 101, no. 4, pp. 738-797, 2012.

[16] N. Cross, "A history of design methodology," in Design methodology and relationships with science, no. 1979, Springer, 1993, pp. 15-28.

[17] J. Daalhuizen, "Method usage in design: How methods function as mental tools for designers - PhD Thesis," Techniche Universiteit Delft, 2014.

[18] S. R. Daly, E. A. Mosyjowski, and C. M. Seifert, "Teaching creativity in engineering courses," J. Eng. Educ., vol. 103, no. 3, pp. 417-449, 2014.

[19] E. Van Dooren, E. Boshuizen, J. Van Merriënboer, T. Asselbergs, and M. Van Dorst, "Making explicit in design education: Generic elements in the design process," Int. J. Technol. Des. Educ., vol. 24, no. 1, pp. 53-71, 2014.

[20] H. L. Dreyfus and S. E. Dreyfus, "Peripheral Vision: Expertise in Real World Contexts," Organ. Stud., vol. 26, no. 5, pp. 779-792, 2005.

[21] C. Eckert, "That which is not form: The practical challenges in using functional concepts in design," Artif. Intell. Eng. Des. Anal. Manuf., vol. 27, no. 03, pp. 217231, 2013.

[22] K. Ehrlenspiel, "On the importance of the unconscious and the cognitive economy in design," in Human Behaviour in Design, U. Lindemann, Ed. SpringerVerlag, 2003, pp. 25-41.

[23] K. A. Ericsson, "Deliberate practice and acquisition of expert performance: A general overview," Acad. Emerg. Med., vol. 15, no. 11, pp. 988-994, 2008.

[24] H. J. Eysenck, "Creativity and Personality: Suggestions for a Theory," Psychol. Inq., vol. 4, no. 3, pp. 143-178, 1993.

[25] E. S. Ferguson, Engineering and the Mind's Eye. Cambridge, MA: MIT Press, 1992.

[26] A. D. De Figueiredo, "Toward an Epistemology of Engineering," Work. Philos. Eng. (WPE 2008), no. November, pp. 94-95, 2008.

[27] G. Fricke, "Successful Individual Approaches in Engineering Design," Res. Eng. Des., vol. 8, pp. 151$165,1996$.

[28] M. H. Göker, "The effects of experience during design 
problem solving," Des. Stud., vol. 18, no. 4, pp. 405426, 1997.

[29] G. Goldschmidt, "Not from Scratch: The DMS Model of Design Creativity," Des. Creat. 2010, pp. 63-70, 2011.

[30] R. Guindon, "Designing the Design Process: Exploiting Opportunistic Thoughts," Human-Computer Interact., vol. 5, no. 2, pp. 305-344, 1990.

[31] J. Günther and K. Ehrlenspiel, "Comparing designers from practice and designers with systematic design education," Des. Stud., vol. 20, no. 5, pp. 439-451, 1999.

[32] Y. Haik and T. M. Shahin, Engineering Design Process, 2nd ed. Stamford, CT: Cengage Learning, 2011.

[33] V. Hubka and W. E. Eder, Theory of technical systems: a total concept theory for engineering design. SpringerVerlag, 1988.

[34] V. Hubka and W. Ernst Eder, "A scientific approach to engineering design," Des. Stud., vol. 8, no. 3, pp. 123 137, 1987.

[35] B. Hyman, Fundamentals of Engineering Design, 2nd ed. Pearson Prentice Hall, 2003.

[36] J. Jansch and H. Birkhofer, "Imparting design methods with the strategies of experts," in International Conference On Engineering Design (ICED'07), 2007, pp. 1-12.

[37] D. G. Jansson and S. M. Smith, "Design fixation," Des. Stud., vol. 12, no. 1, pp. 3-11, 1991.

[38] D. Kahneman and G. Klein, "Conditions for Intuitive Expertise: A Failure to Disagree,” Am. Psychol., vol. 64, no. 6, pp. 515-526, 2009.

[39] B. Kerr and C. Gagliardi, "Measuring Creativity in Research and Practice," in Positive psychological assessment: A handbook of models and measures, S. J. Lopez and C. R. Snyder, Eds. Washington, DC: American Psychological Association, 2003, pp. 155169.

[40] I. Kihlander, "Managing concept decision making in product development practice," 2011.

[41] R. Kimbell and K. Stables, Researching Design Learning: Issues and Findings from Two Decades of Research and Development, vol. 34. Dordrecht, The Netherlands: Springer, 2008.

[42] B. V. Koen, Discussion of the Method, Conducting the Engineer's Approach to Problem Solving. New York, Oxford: Oxford University Press, 2003.

[43] E. Kranakis, "Review of 'Engineering and the Mind's Eye' by Eugene S Ferguson," Technol. Cult., vol. 35, no. 2, pp. 402-404, 1994.

[44] M. Laakso and L. a. Liikkanen, "Dubious role of formal creativity techniques in professional design," ICDC 2012 - 2nd Int. Conf. Des. Creat. Proc., no. December, pp. 55-64, 2012.

[45] B. Lawson, "Schemata, gambits and precedent: Some factors in design expertise," Des. Stud., vol. 25, no. 5, pp. 443-457, 2004.

[46] P. Lloyd, "Storytelling and metaphor in the engineering design process," in Designers: The Key to Successful Product Development, London: Springer-Verlag, 1997, pp. 113-123.

[47] P. Lloyd and P. Scott, "Discovering the design problem," Des. Stud., vol. 15, no. 2, pp. 125-140, 1994.

[48] R. McCormick, "Conceptual and Procedural Knowledge," Int. J. Technol. Des. Educ., vol. 7, no. 1-
2, pp. 141-159, 1997.

[49] G. Miller, "The magical number seven, plus or minus two: some limits on our capacity for processing information," Psychol. Rev., vol. 101, no. 2, pp. 343352, 1956.

[50] J. B. Nikander, L. A. Liikkanen, and M. Laakso, "The preference effect in design concept evaluation," Des. Stud., vol. 35, no. 5, pp. 473-499, Sep. 2014.

[51] K. J. Nisbett and R. Budynas, Shigley's Mechanical Engineering Design. McGraw-Hill Series in Mechanical Engineering, 2014.

[52] B. Oakley, Mindshift: Break through obstacles to learning and discover you hidden potential. Tarcher Pedigree, 2017.

[53] K. N. Otto and K. L. Wood, Product Design: Techniques in Reverse Engineering and New Product Development. Upper Saddle River, NJ: Prentice Hall, 2001.

[54] R. Oxman, "Prior knowledge in design: a dynamic knowledge-based model of design and creativity," Des. Stud., vol. 11, no. 1, pp. 17-28, 1990.

[55] F. Paas, A. Renkl, and J. Sweller, "Cognitive Load Theory and Instructional Design: Recent Developments," Educ. Psychol., vol. 38, no. 1, pp. 1-4, 2003.

[56] G. Pahl and W. Beitz, Engineering Design: A systematic approach. Springer-Verlag (2007, 1996, 1984, 1977).

[57] D. F. Radcliffe and T. Y. Lee, "Design methods used by undergraduate engineering students," Des. Stud., vol. 10, no. 4, pp. 199-207, 1989.

[58] A. E. Samuel, "Product design at an engineering school," in Proceedings ICED 81, Rome Italy, 1981, p. pp 193194.

[59] R. C. Schank, Dynamic memory: A theory of reminding and learning in computers and people. Cambridge University Press, 1982.

[60] S. A. Scribner and M. A. Anderson, "Novice Drafter's Spatial Visualization Development: Influence of Instructional Methods and Individual Learning Styles," J. Ind. Teach. Educ., vol. 42, no. 2, 2005.

[61] M. E. P. Seligman, P. Railton, R. F. Baumeister, and C. Sripada, Homo Prospectus. Oxford University Press, 2016.

[62] M. Stacey and K. Lauche, "Thinking and representing in design," in Design Process Improvement: A Review of Current Practice, J. Clarkson and C. Eckert, Eds. Engineering Design Centre, University of Cambridge, 2005, pp. 198-229.

[63] T. Tomiyama, T. J. van Beek, H. Komoto, and V. D'Amelio, "Making function modeling practically usable," Ai Edam, vol. 27, no. 03, pp. 301-309, 2013.

[64] K. T. Ulrich and S. D. Eppinger, Product Design and Development, 6th ed. McGraw-Hill Education, 2015.

[65] K. T. Ulrich and S. D. Eppinger, Product Design and Development, 5th ed. McGraw-Hill Irwin, 2012.

[66] K. F. Zuga, "Improving Technology Education Research on Cognition," Int. J. Technol. Des. Educ., vol. 14, no. 1, pp. 79-87, 2004. 